\title{
Eicosanoid Activity Inhibition
}

National Cancer Institute

\section{Source}

National Cancer Institute. Eicosanoid Activity Inhibition. NCI Thesaurus. Code C41539.

Through decreased production or release, or enhanced deg radation, Eicosanoid Activity Inhibition involves interference with, or restraint of, the biological function of hormonelike endogenous unsaturated and oxygenated fatty acid derivatives of arachidonic acid (eicosanoids) that act near the site of synthesis and have a specific regulatory effect on the activity of target cells in host defense reactions, immediate hypersensitivity, and inflammation. Eicosanoids include prostaglandins, leukotrienes, thromboxanes, and hydroxyeicosatetraenoic acid compounds. 